\title{
Headphone Device
}

National Cancer Institute

\section{Source}

National Cancer Institute. Headphone Device. NCI Thesaurus. Code C49979.

A device with sound speakers designed to be worn on the head in proximity to the ears. 